\title{
Microstructure and Wear Behavior of CoCrFeMnNbNi High-Entropy Alloy Coating by TIG Cladding
}

\author{
Wen-yi Huo, Hai-fang Shi, Xin Ren, and Jing-yuan Zhang \\ School of Materials Science and Engineering, Liaoning Technical University, Fuxin, Liaoning 123000, China \\ Correspondence should be addressed to Wen-yi Huo; lntuhwy@163.com
}

Received 8 November 2014; Accepted 15 December 2014

Academic Editor: Jiangbo Sha

Copyright ( 2015 Wen-yi Huo et al. This is an open access article distributed under the Creative Commons Attribution License, which permits unrestricted use, distribution, and reproduction in any medium, provided the original work is properly cited.

\begin{abstract}
Alloy cladding coatings are widely prepared on the surface of tools and machines. High-entropy alloys are potential replacements of nickel-, iron-, and cobalt-base alloys in machining due to their excellent strength and toughness. In this work, $\mathrm{CoCrFeMnNbNi}$ HEA coating was produced on AISI 304 steel by tungsten inert gas cladding. The microstructure and wear behavior of the cladding coating were studied by X-ray diffraction, scanning electron microscopy, energy dispersive spectrometer, microhardness tester, pinon-ring wear tester, and 3D confocal laser scanning microscope. The microstructure showed up as a nanoscale lamellar structure matrix which is a face-centered-cubic solid solution and niobium-rich Laves phase. The microhardness of the cladding coating is greater than the structure. The cladding coating has excellent wear resistance under the condition of dry sliding wear, and the microploughing in the worn cladding coating is shallower and finer than the worn structure, which is related to composition changes caused by forming the nanoscale lamellar structure of Laves phase.
\end{abstract}

\section{Introduction}

In 1995, Yeh et al. developed the high-entropy alloy (HEA) system [1-3], which is a multielement system that can crystallize as simple phases, despite containing different elements [4]. They are based on the promising alloy design ideas of configurational entropy maximization. Compared with the classic alloys, they generally have a better performance. The equiatomic and nonequiatomic HEAs which crystallize in the face-centered cubic (FCC) have been paid wide attention owing to their excellent property of toughness, among which the CoCrFeMnNi HEA system is a typical one [5-10]. The low diffusion rate of HEAs at high and low temperatures makes their applications in harsh condition possible [5-7]. From what have been analyzed above, the HEA cladding coating has also been extensively studied and shown to have enormous potential in surface engineering. The excellent properties they showed are the same with the HEAs. However, the HEA cladding coating system is confined to $\mathrm{Al}_{\mathrm{x}} \mathrm{FeCoNiCuCr}$ [11], $\mathrm{FeCoNiCrCu}$ [12], TiVCrAlSi [13, 14], 6FeNiCoCrAlTiSi [15], NiCrAlCoCu [16], NiCrAlCoMo [16], $\mathrm{CoCrCuFeNiNb}_{\mathrm{x}}$ [17], and so on.
Tungsten inert gas (TIG) cladding is one of the common and economical methods of surface treatment and surface alloying, which can easily provide the substrate metallurgical bond with cladding coating. There is always one dominant element in conventional cladding coating systems; however, many multicomponent mixed powders which contain nickel-, iron-, and cobalt-base alloys have been cladded on the substrates. Recently, HEA cladding coatings have been well prepared by TIG cladding [16]. In this study, $\mathrm{CoCrFeMnNbNi}$ HEA coating has been produced on the surface of AISI 304 steel substrate by TIG cladding, and its wear behavior has been researched exhaustively.

\section{Experimental Procedure}

2.1. Preparation of the Cladding Coating. The AISI 304 steel was machined into a rectangular specimen with dimension of $50 \mathrm{~mm} \times 40 \mathrm{~mm} \times 8 \mathrm{~mm}$ as a substrate. Table 1 lists the chemical proportion of the coating material. The Co, $\mathrm{Cr}, \mathrm{Fe}, \mathrm{Mn}, \mathrm{Nb}$, and $\mathrm{Ni}$ powder (purity > $99.9 \mathrm{Wt} . \%$ ) was prepared as raw materials. Figure 1 shows the atomic radii of 
TABLE 1: Chemical composition of the mixed powder.

\begin{tabular}{lcccccc}
\hline Element & $\mathrm{Co}$ & $\mathrm{Cr}$ & $\mathrm{Fe}$ & $\mathrm{Mn}$ & $\mathrm{Nb}$ & $\mathrm{Ni}$ \\
\hline At. [\%] & 16.66 & 16.67 & 16.66 & 16.67 & 16.67 & 16.67 \\
Wt. [\%] & 15.78 & 13.93 & 14.95 & 14.72 & 24.89 & 15.73 \\
\hline
\end{tabular}

TABLE 2: Parameters of the cladding.

\begin{tabular}{lc}
\hline Cladding current $[\mathrm{A}]$ & 210 \\
Traveling speed $[\mathrm{m} / \mathrm{s}]$ & $2 \times 10^{-3}$ \\
Argon, flow rate $[\mathrm{L} / \mathrm{min}]$ & 12 \\
Arc gap $[\mathrm{m}]$ & $3.5 \times 10^{-3}$ \\
Electrode type & $\mathrm{W}-1.5 \%$ lanthanum \\
Electrode polarity & DCSP \\
\hline
\end{tabular}
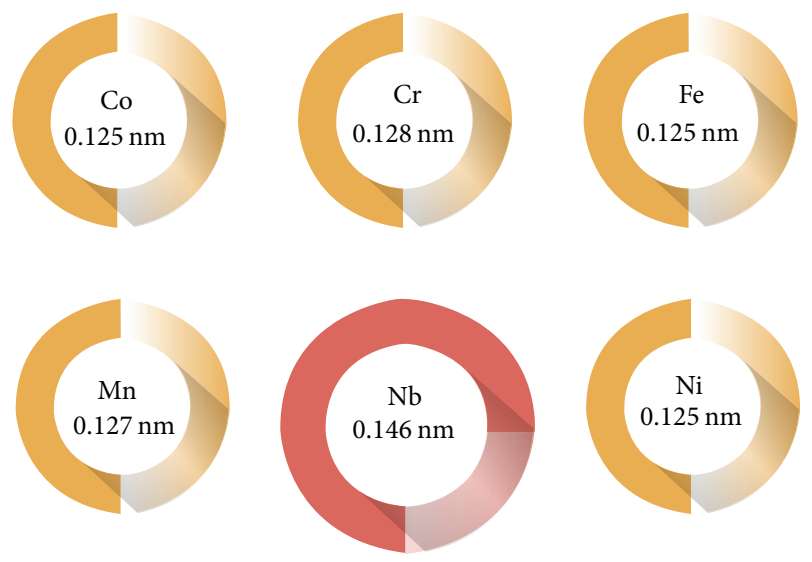

FIgURE 1: Atomic radii of elements.

elements. Apparently, Nb has the largest atomic size among the elements. Even compared with $\mathrm{Nb}$, there is little difference among the atomic radius values of $\mathrm{Co}, \mathrm{Cr}, \mathrm{Fe}, \mathrm{Mn}$, and $\mathrm{Ni}$. So it can be expected that $\mathrm{Nb}$ makes the effect of lattice distortion and solid solution improve to a large extent.

The mixed powder was well mixed without any kind of binders and it was manufactured into small pieces with dimension of $30 \mathrm{~mm} \times 10 \mathrm{~mm} \times 2 \mathrm{~mm}$ through compacting and pressure working. The equipment used in this process was a WE-30 hydraulic universal testing machine with dedicated mold. By using WS-500 inverter DC TIG welder in cladding, under an argon atmosphere, the piece was synthesized on the surface of substrate. Table 2 lists the parameters of the cladding.

2.2. Characterization of the Cladding Coating. The crystalline phases were determined by an X'Pert PRO X-ray diffraction (XRD) for a $2 \theta$ range of $20^{\circ}$ to $80^{\circ}$ using $\mathrm{Cu}-\mathrm{K} \alpha$ radiation. Microstructure was characterized by an EVO MA 10 scanning electron microscope (SEM) and an X-act X-ray energy dispersive spectrometer (EDS). The microhardness along the depth of the cross section was measured by using the HV$1000 \mathrm{Z}$ microhardness tester with a load of $1.96 \mathrm{~N}$. An ML100 pin-on-ring wear tester was used to measure the abrasive wear resistance of the cladding coating under the condition

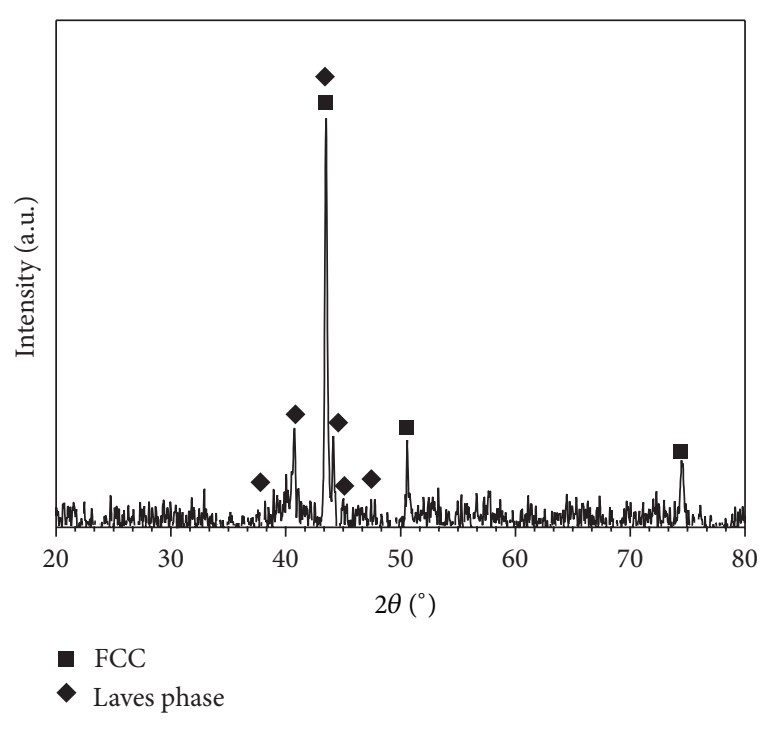

FIGURE 2: XRD pattern of CoCrFeMnNbNi HEA coating.

of dry sliding wear. The sample was electrode-discharge machined to a cylinder with the size of $\Phi 6 \mathrm{~mm} \times 10 \mathrm{~mm}$. The 180 grade silicon carbide sandpaper was used as the friction counterpart. The wear conditions were a sliding speed of $60 \mathrm{r} / \mathrm{min}$, a radial feed rate of $1 \mathrm{~mm} / \mathrm{r}$, a rotating diameter of $70-220 \mathrm{~mm}$, and a normal load of $40 \mathrm{~N}$. The worn surfaces were scanned using a $3 \mathrm{D}$ confocal laser scanning microscope to study the wear behavior of the cladding coating.

\section{Results and Discussion}

3.1. Microstructure. Figure 2 shows the XRD pattern of the CoCrFeMnNbNi HEA coating. A face-centered-cubic (FCC) solid-solution phase and a Laves phase are obtained in the cladding coating due to the high-entropy effect which makes the total number of phases lower than the value of the maximum equilibrium allowed by the Gibbs phase rule. The FCC solid-solution phase is similar with the peak positions of (Fe, Ni) type, while the Laves phase is similar with the peak positions of $\mathrm{Fe}_{2} \mathrm{Nb}$ type.

Figure 3 shows the microstructure of the surface of unetched CoCrFeMnNbNi HEA coating, which is composed of dendritic (DR) and interdendritic (ID) regions. From Figure 3, it can be seen that DR and ID regions are alternately arranged forming a lamellar colony. Its lamellar spacing is about $100 \sim 200 \mathrm{~nm}$. Table 3 shows the chemical proportion of DR and ID. Considered in conjunction with Figure 3, it is obvious that the BSI contrast of DR regions is bright, which indicates that these regions contain much heavier elements. However, ID regions' contrast is dark, which suggests that 
TABLE 3: Chemical proportion of DR and ID (At. \%).

\begin{tabular}{lcccccr}
\hline Element & $\mathrm{Co}$ & $\mathrm{Cr}$ & $\mathrm{Fe}$ & $\mathrm{Mn}$ & $\mathrm{Nb}$ & $\mathrm{Ni}$ \\
\hline $\mathrm{DR}$ & 8.77 & 16.77 & 38.16 & 9.50 & 15.31 & 1.49 \\
ID & 8.71 & 19.12 & 40.75 & 10.88 & 6.32 & 14.22 \\
\hline
\end{tabular}

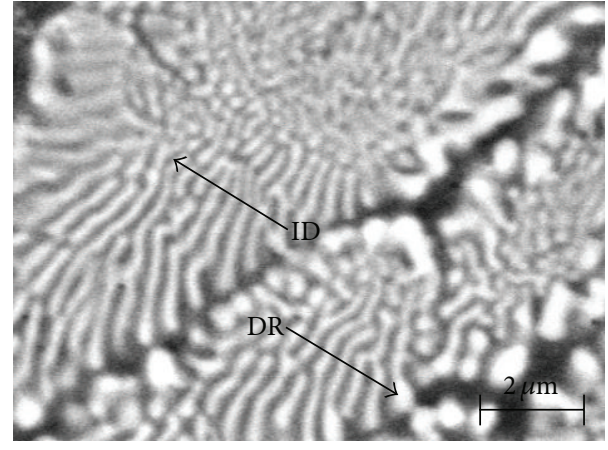

FIGURE 3: Microstructure of the surface of CoCrFeMnNbNi HEA coating.

these regions contain less heavier elements. The EDS analysis suggests that $\mathrm{DR}$ regions are enriched with $\mathrm{Nb}$, while ID regions are depleted with $\mathrm{Nb}$. Figure 2 shows that the cladding coating is two phases: it is reasonable to infer that DR regions are Laves phase and ID regions are FCC solidsolution phase in the light of different content of niobium. The adding of $\mathrm{Nb}$ can effectively refine microstructure which may be attributed to the segregation of $\mathrm{Nb}$ in $\mathrm{DR}$ regions. The nucleation and growth of FCC solid-solution phase are retarded, which can be attributed to $\mathrm{Nb}$ solute atoms segregation in the forefront of solid-liquid (S-L) interface, and grain boundaries are favorable position for the location of niobium atoms [17]. In addition, $\mathrm{Fe}, \mathrm{Cr}$, and $\mathrm{Ni}$, the principal elements of the AISI 304 steel substrate, participate in cladding process during the TIG cladding. These elements have diffused from the substrate to the coating surface to make their contents in the surface of cladding coating rise.

3.2. Microhardness and Wear Behavior. Figure 4 shows the microhardness profile of $\mathrm{CoCrFeMnNbNi} \mathrm{HEA} \mathrm{coating.} \mathrm{As}$ what can be seen in it, the cladding coating presents a greater microhardness compared to the substrate. Excluding the high-entropy effect, the improvement in hardness can be ascribed to the Laves phase. The niobium added makes the crystal structure form the nanoscale Laves phase and reinforces the solution strengthening. The microhardness of transition zone is less than that of cladding coating surface for the reason that elements of the substrate (such as $\mathrm{Fe}, \mathrm{Cr}$, and $\mathrm{Ni}$ ) have been excessively diffused during the process of solidification. It helps to enhance the cladding coating adhesion.

Figure 5 shows the mass losses of cladding coating and substrate as a function of sliding time. The $\mathrm{CoCrFeMnNbNi}$ HEA coating exhibited much lower mass loss compared with AISI 304 steel. It is clear that it has a lower wear rate than AISI 304 steel. The existence of Laves phase with nanoscale

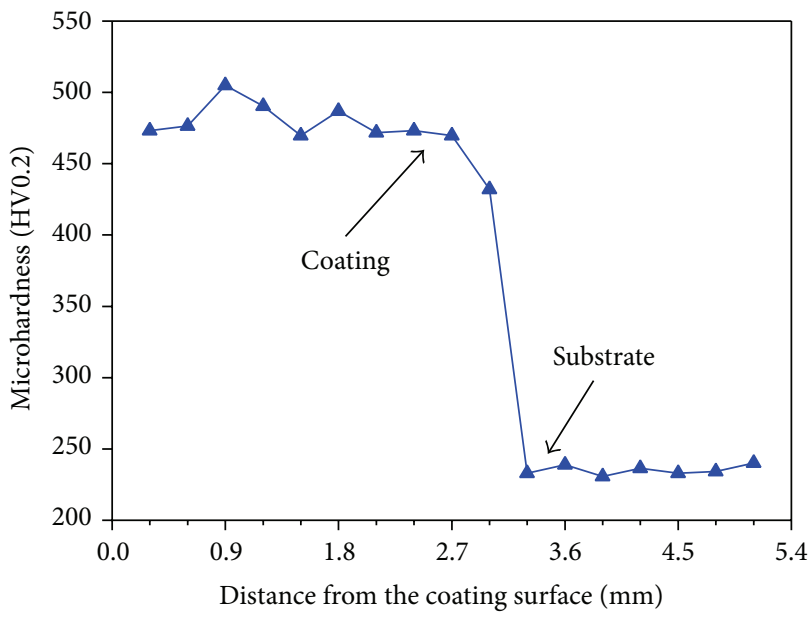

FIgURE 4: Microhardness profile of CoCrFeMnNbNi HEA coating.

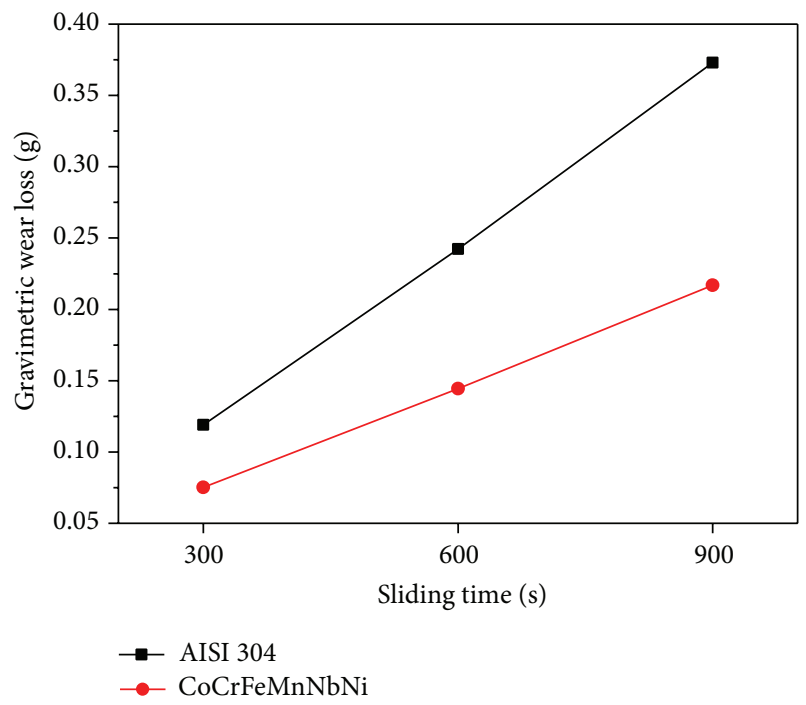

Figure 5: Mass losses of CoCrFeMnNbNi HEA coating and substrate as a function of sliding time.

lamellar spacing leads to higher load capacity and protection of the surface against sliding wear scratches. Hard Laves phase resists destructive action during sliding and protects the surface against severe plastic deformation. The FCC solidsolution phase with great toughness protects the surface against brittle fracture.

Figure 6 shows the 3D microstructure of worn surfaces of AISI 304 steel and the CoCrFeMnNbNi HEA coating. On the worn surface of AISI 304 steel, microploughing is obvious. This can be attributed to plastic deformation during sliding. 


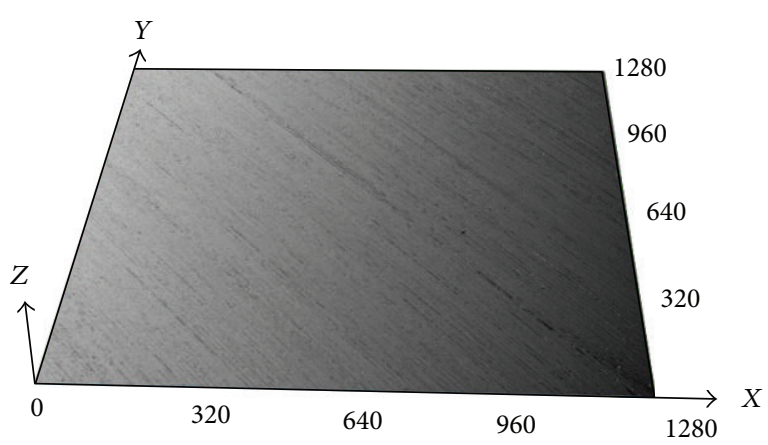
$-103$

(a) AISI 304 steel

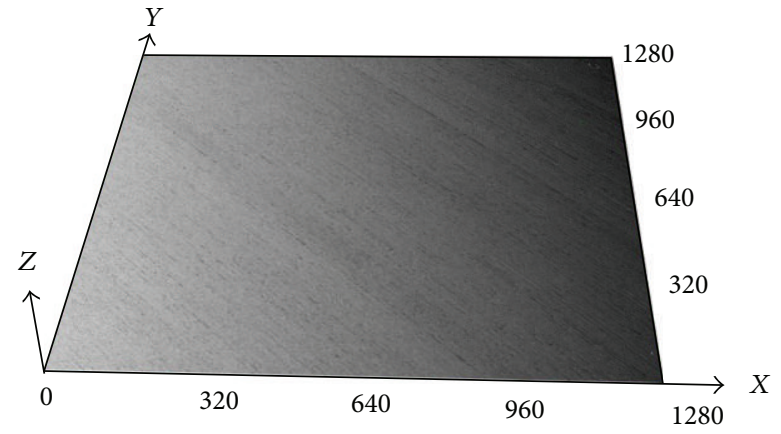

0

(b) CoCrFeMnNbNi HEA coating

FIGURE 6: 3D microstructure of worn surfaces of AISI 304 steel and CoCrFeMnNbNi HEA coating $(\mu \mathrm{m})$.

It is the typical characteristic of abrasive wear mechanism. The microploughing on worn surfaces of the cladding coating is shallower and finer compared with AISI 304 steel.

\section{Conclusion}

The microhardness of the CoCrFeMnNbNi high-entropy alloy coating produced by TIG cladding increased significantly compared to the AISI 304 steel substrate. The microstructure showed up as a nanoscale lamellar structure matrix which is a face-centered-cubic solid solution and niobium-rich Laves phase. It is due to the fact that added $\mathrm{Nb}$ makes the nucleation and growth of face-centeredcubic solid-solution phase retard. The cladding coating has excellent wear resistance under the condition of dry sliding wear, which is due to the fact that hard Laves phase resists destructive action during sliding and protects the surface against severe plastic deformation and the FCC solid-solution phase with a great toughness protects the surface against brittle fracture.

\section{Conflict of Interests}

The authors declare that there is no conflict of interests regarding the publication of this paper.

\section{References}

[1] J.-W. Yeh, S.-K. Chen, S.-J. Lin et al., "Nanostructured highentropy alloys with multiple principal elements: novel alloy design concepts and outcomes," Advanced Engineering Materials, vol. 6, no. 5, pp. 299-274, 2004.

[2] C.-J. Tong, Y.-L. Chen, S.-K. Chen et al., "Microstructure characterization of $\mathrm{Al}_{x}$ CoCrCuFeNi high-entropy alloy system with multiprincipal elements," Metallurgical and Materials Transactions A, vol. 36, no. 4, pp. 881-893, 2005.

[3] J.-M. Wu, S.-J. Lin, J.-W. Yeh, S.-K. Chen, Y.-S. Huang, and H.C. Chen, "Adhesive wear behavior of $\mathrm{Al}_{x} \mathrm{CoCrCuFeNi}$ highentropy alloys as a function of aluminum content," Wear, vol. 261, no. 5-6, pp. 513-519, 2006.
[4] Y. Zhang, T. T. Zuo, Z. Tang et al., "Microstructures and properties of high-entropy alloys," Progress in Materials Science, vol. 61, pp. 1-93, 2014.

[5] B. Gludovatz, A. Hohenwarter, D. Catoor, E. H. Chang, E. P. George, and R. O. Ritchie, "A fracture-resistant high-entropy alloy for cryogenic applications," Science, vol. 345, no. 47, pp. 1153-1158, 2014.

[6] F. Otto, A. Dlouhý, C. Somsen, H. Bei, G. Eggeler, and E. P. George, "The influences of temperature and microstructure on the tensile properties of a CoCrFeMnNi high-entropy alloy," Acta Materialia, vol. 61, no. 15, pp. 5743-5755, 2013.

[7] J. Y. He, C. Zhu, D. Q. Zhou, W. H. Liu, T. G. Nieh, and Z. P. $\mathrm{Lu}$, "Steady state flow of the FeCoNiCrMn high entropy alloy at elevated temperatures," Intermetallics, vol. 55, pp. 9-14, 2014.

[8] K.-Y. Tsai, M.-H. Tsai, and J.-W. Yeh, "Sluggish diffusion in CoCr-Fe-Mn-Ni high-entropy alloys," Acta Materialia, vol. 61, no. 13, pp. 4887-4897, 2013.

[9] M. J. Yao, K. G. Pradeep, C. C. Tasan, and D. Raabe, "A novel, single phase, non-equiatomic $\mathrm{FeMnNiCoCr}$ high-entropy alloy with exceptional phase stability and tensile ductility," Scripta Materialia, vol. 72-73, pp. 5-8, 2014.

[10] C. Zhu, Z. P. Lu, and T. G. Nieh, "Incipient plasticity and dislocation nucleation of FeCoCrNiMn high-entropy alloy," Acta Materialia, vol. 61, no. 8, pp. 2993-3001, 2013.

[11] X. Y. Ye, M. X. Ma, W. J. Liu, M. L. Zhong, Y. X. Liu, and Q. $\mathrm{W}$. Wu, "Synthesis and characterization of high-entropy alloy FeCoNiCuCr by laser cladding," Advances in Materials Science and Engineering, vol. 2011, Article ID 485942, 7 pages, 2011.

[12] H. Zhang, Y. Pan, and Y.-Z. He, "Synthesis and characterization of $\mathrm{FeCoNiCrCu}$ high-entropy alloy coating by laser cladding," Materials \& Design, vol. 32, no. 4, pp. 1910-1915, 2011.

[13] C. Huang, Y. Zhang, J. Shen, and R. Vilar, "Thermal stability and oxidation resistance of laser clad TiVCrAlSi high entropy alloy coatings on Ti-6Al-4V alloy," Surface and Coatings Technology, vol. 206, no. 6, pp. 1389-1395, 2011.

[14] C. Huang, Y. Zhang, R. Vilar, and J. Shen, "Dry sliding wear behavior of laser clad TiVCrAlSi high entropy alloy coatings on Ti-6Al-4V substrate," Materials \& Design, vol. 41, pp. 338-343, 2012. 
[15] H. Zhang, Y. Pan, and Y. He, "Effects of annealing on the microstructure and properties of $6 \mathrm{FeNiCoCrAlTiSi}$ highentropy alloy coating prepared by laser cladding," Journal of Thermal Spray Technology, vol. 20, no. 5, pp. 1049-1055, 2011.

[16] Y. C. Lin and Y. H. Cho, "Elucidating the microstructural and tribological characteristics of NiCrAlCoCu and NiCrAlCoMo multicomponent alloy clad layers synthesized in situ," Surface and Coatings Technology, vol. 203, no. 12, pp. 1694-1701, 2009.

[17] J. B. Cheng, X. B. Liang, and B. S. Xu, "Effect of Nb addition on the structure and mechanical behaviors of CoCrCuFeNi highentropy alloy coatings," Surface and Coatings Technology, vol. 240, pp. 184-190, 2014. 

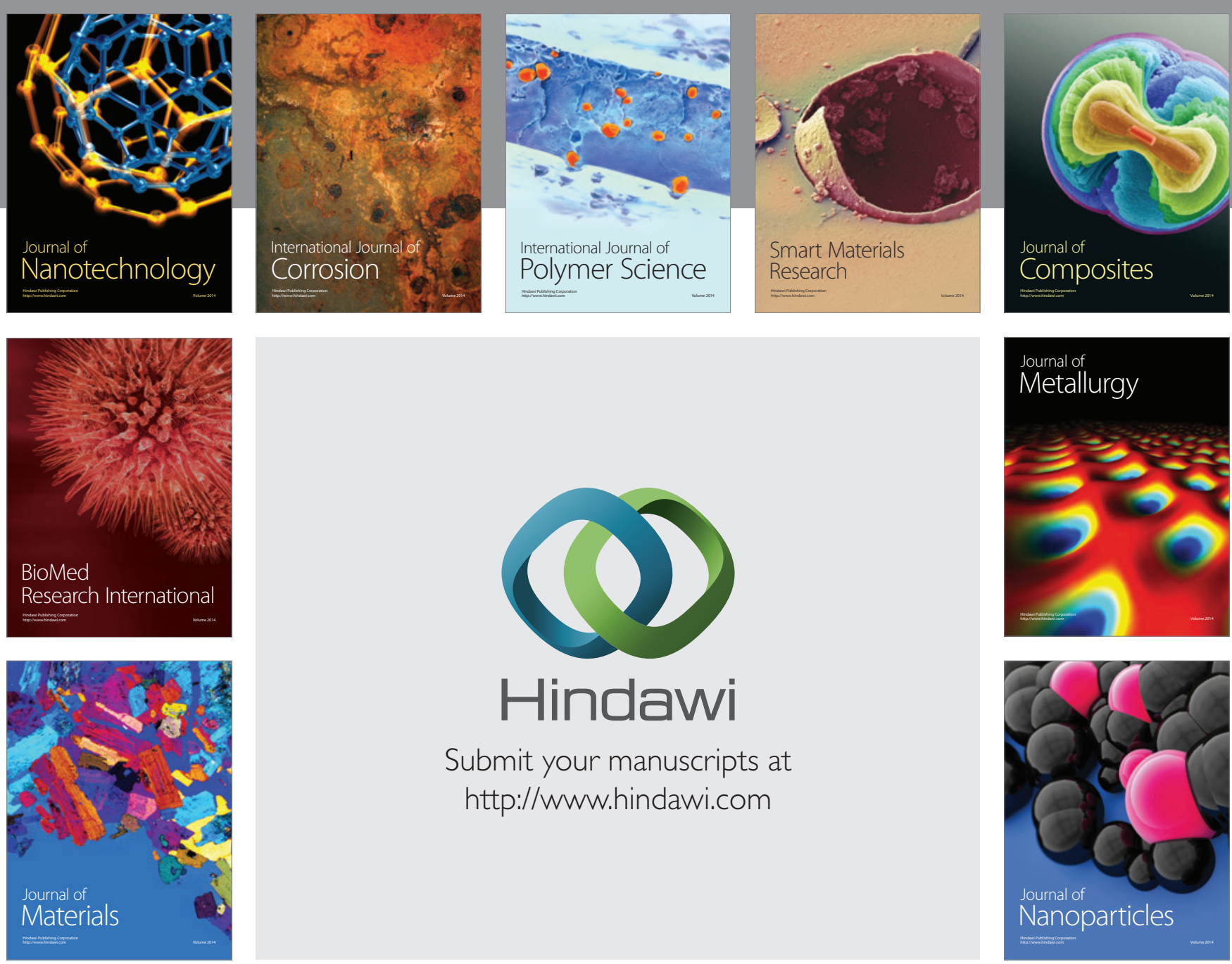

Submit your manuscripts at http://www.hindawi.com
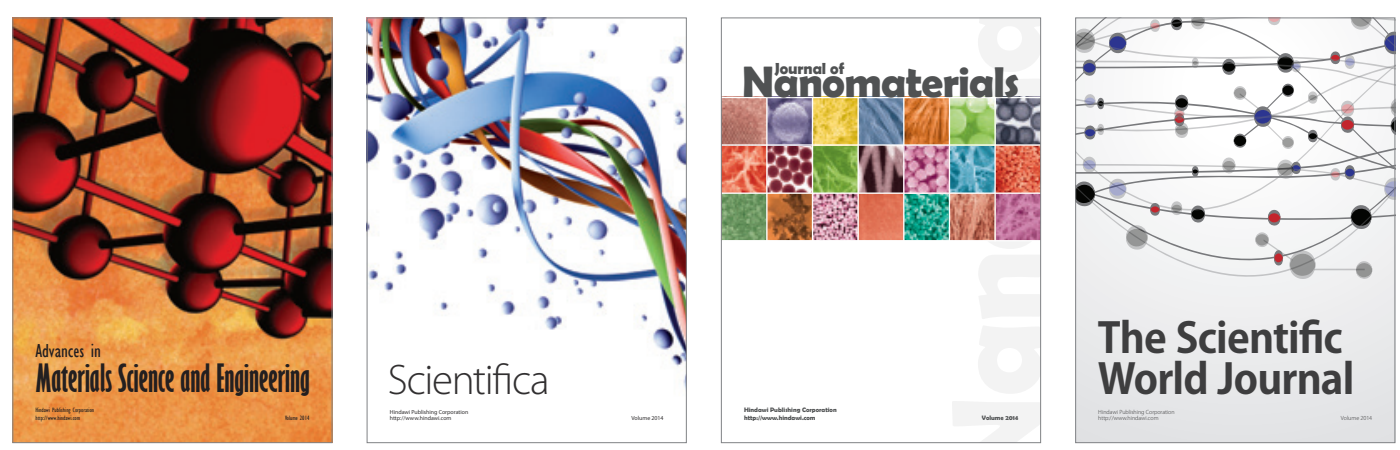

\section{The Scientific World Journal}
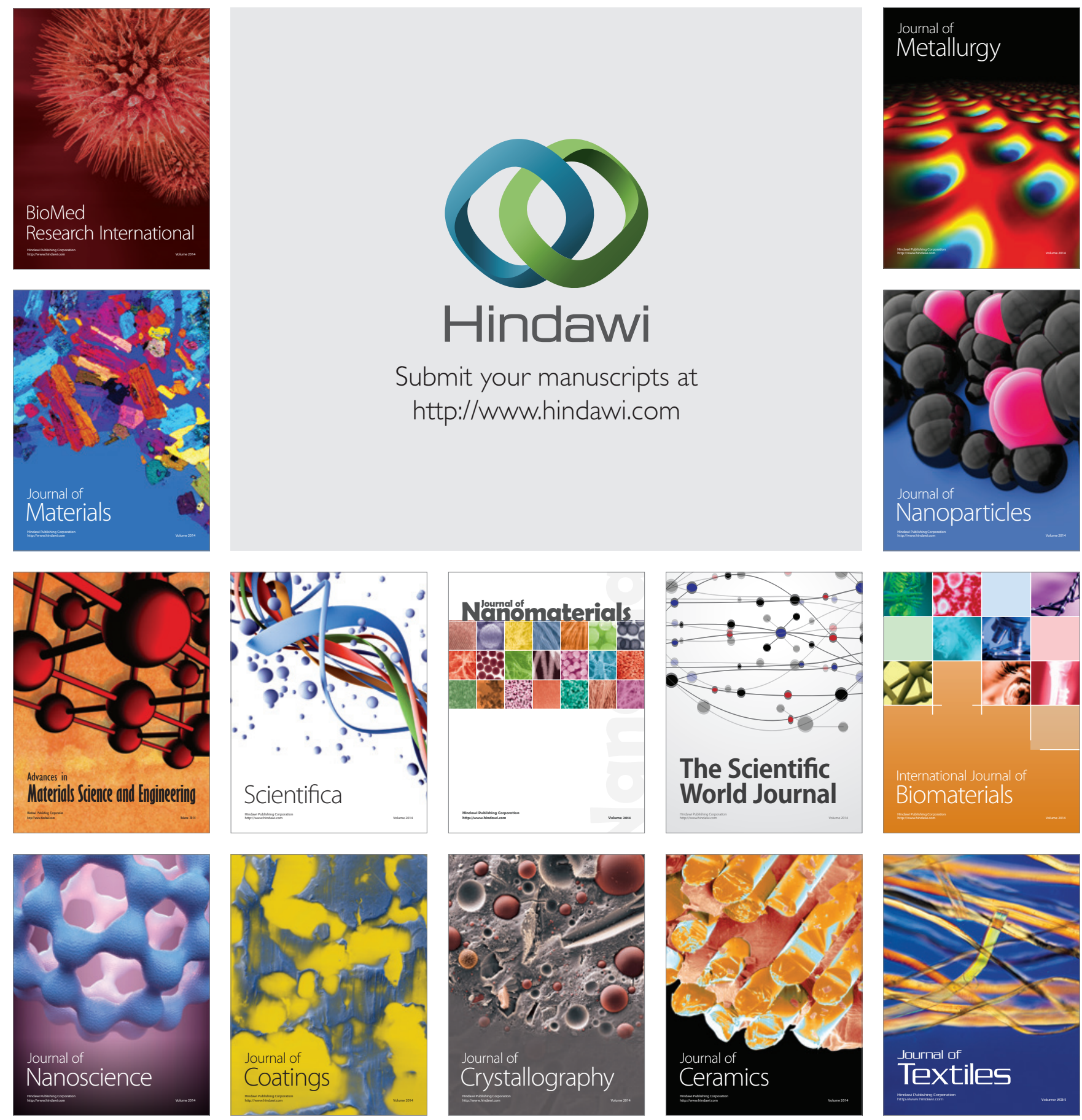